\title{
Cation and anion vacancies in cubic molybdenum nitride
}

\author{
B. D. Ozsdolay, K. Balasubramanian, and D. Gall
}

Epitaxial $\mathrm{MoN}_{x}$ layers deposited on $\mathrm{MgO}(001)$ by reactive magnetron sputtering in 20 mTorr $\mathrm{N}_{2}$ at $T_{\mathrm{s}}=600-1000{ }^{\circ} \mathrm{C}$ exhibit a cubic rock-salt type structure, a $\mathrm{N}$-to-Mo ratio that decreases from $x=1.25-0.69$ with increasing $T_{\mathrm{s}}$, and a lattice constant that simultaneously decreases from 4.26-4.16 ̊. A combination of composition, thickness, lattice-constant, and atomic area-density measurements indicate that the rock-salt structure contains both anion and cation vacancies, with the Mo site occupancy $X_{\text {Mo }}$ decreasing from $0.89 \pm 0.06$ to $0.70 \pm 0.04$ while the $\mathrm{N}$ site occupancy $X_{\mathrm{N}}$ increases from $0.60 \pm 0.04$ to $0.88 \pm 0.04$, as $x$ increases from $0.69-1.25$. Density functional calculations for over 200 cubic $\mathrm{MoN}_{x}$ configurations confirm the energetic stability of both cation and anion vacancies and predict $X_{\mathrm{Mo}}$ to decrease from 1.00 to 0.67 for $x=$ $0.54-1.50$, while $X_{\mathrm{N}}$ increases from 0.50 to 1.00 for $x=0.50-1.36$. The simulations are in good agreement with experiments and indicate a preference for a $75 \%$ site occupancy on both sublattices for compositions near stoichiometry, with $X_{\mathrm{Mo}}=0.75$ for $x=1.00-1.22$ and $X_{\mathrm{N}}=0.75$ for $x=0.86-1.00$. Correspondingly, cubic stoichiometric $\mathrm{MoN}$ is most stable in the $\mathrm{NbO}$ structure.

Keywords: MoN; vacancies; transition metal nitrides; sputter deposition; reactive sputtering; thin films 


\section{Introduction}

Transition metal nitrides have found wide use as hard and decorative coatings [1-3] due to their high hardness and high temperature stability [4,5]. Many transition metal nitrides crystallize in the cubic rock-salt structure including TiN [6], $\mathrm{CrN}$ [7], $\mathrm{ScN}$ [8], VN [9], NbN [10], TaN [11], ZrN [12], and HfN [13]. The layers often exhibit considerable deviations from stoichiometry $[6,11]$ with the nitrogen to cation ratio $x$ either below or above unity. This is typically attributed to nitrogen vacancies or interstitials [14-19], while anti-site substitutions have also been proposed [11]. In contrast, only a few studies have considered the possibility of a significant concentration of cation vacancies [6,14]. Nevertheless, the introduction of metal vacancies may occur for some transition metal nitrides due to kinetic barriers during growth or even due to thermodynamic driving forces [10], and are expected to strongly affect physical properties. This has recently been shown for the W-N system from both experimental and computational studies [20,21], suggesting considerable vacancy concentrations at both anion and cation sites $[21,22]$. Consequently, it is interesting to also quantify metal and nitrogen vacancy concentrations in $\mathrm{MoN}_{x}$, which is isoelectric with $\mathrm{WN}_{x}$.

The Mo-N system has been reported to crystallize in various phases, with the most common being (i) BCC Mo with a possible small amount of dissolved nitrogen, (ii) facecentered cubic $\gamma-\mathrm{Mo}_{2} \mathrm{~N}_{x}$, (iii) body-centered tetragonal $\beta-\mathrm{Mo}_{2} \mathrm{~N}_{x}$, and (iv) hexagonal $\delta$-MoN [2327]. Interestingly, the $\beta$ and $\gamma$ phases have nominally the same composition range, with some experiments reporting the $\gamma$ and $\beta$ phase forming below and above a critical temperature of $775^{\circ} \mathrm{C}$ [28], in apparent contradiction to the reported Mo-N phase diagram which suggests $\gamma$ to be the high-temperature phase and $\beta$ the low-temperature phase [29]. The challenge to experimentally distinguish between these two phases which exhibit nearly identical x-ray 
diffraction (XRD) peak positions has been overcome by asymmetric XRD analyses which, in particular, identify the tetragonal $\beta$ phase [26]. It is frequently assumed in the cases of both the $\gamma$ and the $\beta$ phases that nitrogen vacancies or interstitials alone are sufficient to account for variations in composition, while cation vacancies are not typically taken into account [17]. Recent computational studies $[21,30]$ propose also the cubic NbO structure, which can be described as a cubic $\mathrm{NaCl}$ structure for which a regular array of $25 \%$ of both cation and anion sites are vacant.

$\mathrm{MoN}_{x}$ layers have been deposited using a range of methods and processing parameters, leading to different compositions and phases. More specifically, reactive DC sputtering [2325,28,31-39] yields $\operatorname{MoN}_{x}$ with $x=1.08$ in the $\gamma$ phase (with a small amount of possible $\delta$ phase) using $60 \mathrm{sccm}$ of $\mathrm{N}_{2}$ gas flow and $55 \mathrm{sccm}$ of Ar gas flow as well as a $-50 \mathrm{~V}$ substrate bias [31], $x$ $=0-0.54$ in the $\gamma$ phase using $0-26 \%$ of $\mathrm{N}_{2}$ process gas [33] and also from $0-0.35$ in the $\gamma$ phase with varying $\mathrm{N}_{2} /\left(\mathrm{Ar}+\mathrm{N}_{2}\right)$ gas ratio [37]. RF sputtering [40-42] results in $x=0.49-0.67$ in the $\gamma$ phase [41], $x=0.55-0.9$ in the $\gamma$ phase and $x=0.9-1.02$ in the $\delta$ phase [40], and $x=0.9-1.8$ in the B1-MoN phase, which can be described as a cubic variant of the $\gamma$ phase [42]. Other physical vapor deposition techniques such as ion beam assisted deposition (IBAD) [43,44], cathodic arc evaporation [27,45-47], pulsed laser deposition (PLD) [26,48,49], and molecular beam epitaxy [50] have also been employed to deposit $\mathrm{MoN}_{x}$ layers, yielding $x=0.5-1.1$ by IBAD [43] to 0.86-1.03 for a slightly tetragonally distorted $\gamma$ phase deposited by PLD [48], 0.43 for the $\beta$ phase deposited by PLD [26], or 0.2-0.5 by PLD [49], to $\gamma$ phase $\mathrm{MoN}_{x}$ with $x=0.7-1.4$ by MBE [50], for which the $x=0.7$ sample showed a slightly distorted cubic structure. In addition, chemical vapor deposition techniques [51,52] have been used to prepare $\gamma$ phase $\mathrm{MoN}_{x}$ with $x=0-0.5$ or a mixture of $\gamma-\mathrm{MoN}_{x}$ and $\delta$-MoN with $x=0.9-1.05$ [52], while polymer-assisted deposition using 
ethylenediaminetetraacetic acid and polyethyleneimine and annealing in ammonia gas at up to $950{ }^{\circ} \mathrm{C}$ has been reported to yield epitaxial $\mathrm{MoN}$ layers on both cubic $\mathrm{SrTiO}_{3}$ and c-plane hexagonal $\mathrm{Al}_{2} \mathrm{O}_{3}$ substrates [53], and nitridation of a Mo surface has been achieved in an expanding microwave plasma [54].

In this study, we report on the deposition of $\mathrm{MoN}_{x} / \mathrm{MgO}(001)$ by reactive $\mathrm{DC}$ magnetron sputtering in 20 mTorr $\mathrm{N}_{2}$. All layers show only a $002 \gamma-\mathrm{MoN}_{x}$ XRD peak with lattice constants that vary with increasing growth temperature from 4.26-4.16 $\AA$, while the nitrogen-tomolybdenum ratio decreases from $x=1.25-0.69$. The molybdenum area density of the layers is relatively constant while the density increases with increasing $T_{s}$, suggesting filling of Movacancies. Correspondingly, Mo-site occupancies increase from 0.70-0.89 and N-site occupancies decrease from 0.88-0.60, indicating that nitrogen is lost from the layers with increasing $T_{s}$. Density functional theory (DFT) calculations of cubic $\gamma-\mathrm{MoN}_{x}$ quantitatively confirm the experimental results, in particular the simultaneous presence of both cation and anion vacancies and the decrease and increase of Mo and $\mathrm{N}$ site occupancies with increasing $x$, respectively.

\section{Experimental and Computational Procedure}

$\mathrm{MoN}_{x}$ layers were deposited on $\mathrm{MgO}(001)$ substrates in a load-locked ultra-high vacuum dc magnetron sputtering system with a base pressure of $<10^{-9}$ torr $[10,55,56]$. The substrates are one-side polished $10 \times 10 \times 0.5 \mathrm{~mm}^{3}$ wafers that were cleaned in successive rinses of trichloroethylene, acetone, isopropanol, and deionized water, blown dry with dry $\mathrm{N}_{2}$, attached to a Mo block with silver paint, loaded into the system through a load-lock chamber, and thermally degassed at $900{ }^{\circ} \mathrm{C}$ for 1 hour. The substrate temperature $T_{s}$ was measured by a thermocouple 
below the sample stage that was cross-calibrated with a pyrometer focusing on the sample surface. The temperature was adjusted to the desired $T_{s}=600-1000{ }^{\circ} \mathrm{C}$ prior to deposition from a 99.95\%-pure 51-mm-diameter Mo target which was sputter etched before deposition for 5 minutes with a shutter shielding the substrate. The target was facing the substrate at a $9 \mathrm{~cm}$ distance and from a $45^{\circ}$ angle, with the substrate being continuously rotated at 60 rotations per minute to increase thickness uniformity. All depositions were done in 20 mTorr $99.999 \%$ pure $\mathrm{N}_{2}$ and using a constant dc power of $300 \mathrm{~W}$ which was applied to the magnetron for a duration of $6.00 \mathrm{~min}$, resulting a layer thickness ranging from $69-98 \mathrm{~nm}$ corresponding to a temperaturedependent deposition rate of $11.5-16.3 \mathrm{~nm} / \mathrm{min}$.

X-ray diffraction was done in a Panalytical X'Pert PRO MPD system with a $\mathrm{Cu} \mathrm{K}_{\alpha} \lambda=$ $1.5418 \AA$ source yielding a $1^{\circ}$ divergent incident beam limited by an incident slit. $\theta-2 \theta$ scans were collected over a $2 \theta$ range from $5^{\circ}-80^{\circ}$ using the Bragg-Brentano geometry and a PixCEL solid-state line detector. The $2 \theta$-values were calibrated using the substrate peak position, that is, $2 \theta$ was set to the literature value of $42.909^{\circ}$ at the measured positions of the $\mathrm{MgO} 002$ reflection measured using $\mathrm{Cu} \mathrm{K} \alpha_{1}$ X-rays. X-ray reflectivity (XRR) measurements were collected using a parabolic x-ray mirror with a divergence of $0.055^{\circ}$ and a scintillator point detector. XRR data was analyzed by curve fitting using the recursive theory of Parrat based on the Fresnel reflectivity formalism, assuming a Gaussian distribution to model the surface and interface roughness.[57] Rutherford backscattering spectroscopy (RBS) measurements were collected using a $2.0 \mathrm{MeV}{ }^{4} \mathrm{He}^{+}$beam incident at an angle of $6^{\circ}$ to the surface normal with the detector set at a scattering angle of $166^{\circ}$. The sample was continuously rotated to minimize the artifacts due to ion channeling. The RBS spectra were analyzed using the RUMP simulation software for curve fitting, in order to determine the area density of Mo atoms and the N-to-Mo ratio $x$. 
First-principles DFT calculations are performed using the Vienna ab initio simulation package (VASP), employing periodic boundary conditions, a plane wave basis set, the PerdewBurke-Ernzerhof generalized gradient approximation exchange correlation functional [58], and the projector-augmented wave method [59]. All computational parameters are chosen such that calculated total energy differences are converged to within $1 \mathrm{meV} / \mathrm{atom}$. This includes a $500 \mathrm{eV}$ cut-off energy for the plane-wave basis set expansion and $\Gamma$-centered $k$-point grids with, for example, $8 \times 8 \times 8 k$-points for 32 -atom and 24 -atom supercells or $10 \times 10 \times 10 k$-points for 16 -atom supercells. Mo $4 p, 4 d$, and $5 s$ electrons are explicitly calculated, that is, they are not included in the core of the pseudo potential. Test calculations which explicitly calculate the Mo $4 s$ electrons result in $\sim 7 \mathrm{meV}$ per Mo-atom higher formation energies for all tested nitride configurations, such that this error is not expected to affect the relative energies between different reported configurations.

$\mathrm{MoN}_{x}$ is simulated using supercells of stoichiometric rocksalt-structure MoN for which some Mo and/or $\mathrm{N}$ atoms are removed to form cation and/or anion vacancies, respectively. Various supercell sizes and geometries are used to sample diverse vacancy concentrations and ordering, while keeping the supercell size relatively small. Supercells include (i) the conventional 8-atom cell with basis vectors [100], [010], and [001]; (ii) a symmetric 16-atom cell

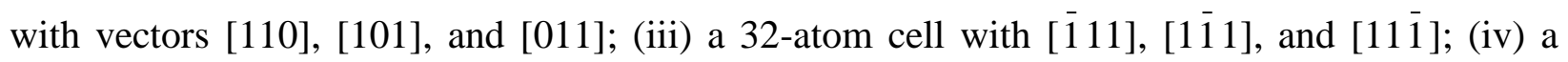
hexagonal-type 24-atom cell with [111], [110], and [101̄]; as well as less conventional supercells

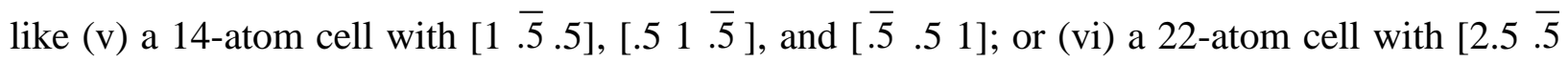
0], [120], and [1.5 0 .5]; or (vii) a 30-atom cell with [1.5 .5 0], [120], and [.5 1 1.5]; or (viii) a

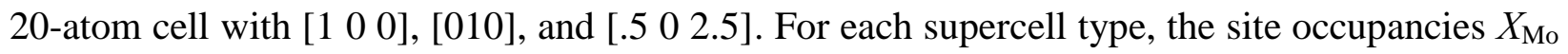
and $X_{\mathrm{N}}$ for Mo atoms on cation sites and $\mathrm{N}$ atoms on anion sites was varied from 0.5 to 1 . For 
example, simulated cells for calculations with the 32-atom-cell mentioned above include 8 to 16 Mo atoms on cation sites and 8 to $16 \mathrm{~N}$ atoms on anion sites of the $\mathrm{NaCl}$-structure lattice. For a given number of Mo and $\mathrm{N}$ atoms, the lattice sites are populated such that the distance between any vacancies is maximized, as this was found to minimize the calculated total energy. Multiple calculations for the same supercell-size and the same number of Mo and $\mathrm{N}$ atoms are performed if it is not a priori evident which configuration results in the lowest energy. Only the lowest energy configuration is reported here.

For all simulated configurations, atomic positions and the supercell volume are iteratively relaxed, while the cell shape is kept fixed. All simulations use as starting point the $\mathrm{NaCl}$ structure lattice. Therefore, all configurations are for a cubic crystal structure even if the simulated cell (and therefore the vacancy lattice) have not a cubic symmetry.

The cohesive energy $E_{\mathrm{c}}$ for the different structures is determined relative to BCC Mo and molecular nitrogen. That is, $E_{\mathrm{c}}=E-N_{\mathrm{Mo}} \mu_{\mathrm{Mo}}-1 / 2 N_{\mathrm{N}} \mu_{\mathrm{N} 2}$, where $E$ is the calculated energy for a specific supercell containing $N_{\mathrm{Mo}}$ molybdenum and $N_{\mathrm{N}}$ nitrogen atoms, while $\mu_{\mathrm{Mo}}$ and $\mu_{\mathrm{N} 2}$ are the Mo and $\mathrm{N}_{2}$ chemical potentials corresponding to the calculated energy of a one-atom BCC Mo unit cell and an isolated $\mathrm{N}_{2}$ molecule, respectively. All calculations are for zero temperature. Considering finite temperatures would add correction terms, with the largest being associated with the entropy of the $\mathrm{N}_{2}$ gas [10], driving the system at high temperature towards phase separation into $\mathrm{N}_{2}$ gas and a reduction in $x$ in the solid $\mathrm{MoN}_{x}$ phase. In order to directly compare formation energies $E_{f}$ of different compositions, the calculated cohesive energies are presented in this paper as energy per atom, i.e. $E_{f}=E_{\mathrm{c}} /\left(N_{\mathrm{Mo}}+N_{\mathrm{N}}\right)$.

\section{Results and Discussion}


Figure 1 is a plot of the $\mathrm{MoN}_{x}$ lattice constant as a function of the growth temperature $T_{s}$ $=600-1000{ }^{\circ} \mathrm{C}$, as determined from X-ray diffraction measurements of $\mathrm{MoN}_{x} / \mathrm{MgO}(001)$ layers. A small section from a typical $\theta-2 \theta$ scan in shown in the inset, in this case from a $68.9 \pm 0.1 \mathrm{~nm}$ thick layer grown at $1000{ }^{\circ} \mathrm{C}$. It exhibits a double peak feature at $2 \theta=42.909^{\circ}$ and $43.021^{\circ}$, which is associated with the $\mathrm{MgO} 002$ substrate reflection of the $\mathrm{Cu} \mathrm{K} \alpha_{1}$ and $\mathrm{K} \alpha_{2}$ lines, respectively, and a broader and 60 times weaker a peak at $2 \theta=43.46^{\circ}$ which is visible in the inset from the 30-times-magnified (red) curve and is labeled as $\mathrm{MoN}_{x} 002$. No other peaks could be detected over the entire $2 \theta$ range from $5-80^{\circ}$, indicating a 002 texture and, in combination with asymmetric scans (not shown), confirming that the layer is epitaxial $\operatorname{MoN}_{x}(001)$. The diffraction patterns from the other samples also show only a single $\mathrm{MoN}_{x}$ peak. However, its position shifts as a function of growth temperature from $2 \theta=42.43 \pm 0.01^{\circ}$ for $T_{s}=600{ }^{\circ} \mathrm{C}$ to $2 \theta=$ $42.72 \pm 0.07^{\circ}, 42.82 \pm 0.10^{\circ}$, and $43.42 \pm 0.25^{\circ}$ for $T_{s}=700,800$, and $900{ }^{\circ} \mathrm{C}$. The peaks for $T_{s}=$ 700-900 ${ }^{\circ} \mathrm{C}$ partially overlap with the substrate peaks, causing a larger uncertainty in the determination of their position than for $T_{s}=600$ and $1000{ }^{\circ} \mathrm{C}$, as indicated with the error bars. The detected $\mathrm{MoN}_{x}$ peaks are close to the reported cubic $\gamma-\mathrm{Mo}_{3} \mathrm{~N}_{2} 002$ peak position at $2 \theta=$ $43.418^{\circ}$ [JCPDS 01-089-3712] as well as the 200 and 400 reflections of the tetragonal $\beta-\mathrm{Mo}_{2} \mathrm{~N}$ structure with a ratio of $a /(c / 2)=1.05$ and $2 \theta=43.038^{\circ}$ and $45.306^{\circ}$, respectively [JCPDS 01075-1150]. However, our asymmetric XRD scans (not shown) are inconsistent with a tetragonal structure, such that we attribute the detected peaks to cubic $\mathrm{MoN}_{x} 002$, and use their position to determine the lattice constant, as plotted in Fig. 1. More specifically, the plotted values are the out-of-plane lattice constants which decrease from $a_{\perp}=4.258 \AA$ for $T_{s}=600{ }^{\circ} \mathrm{C}$ to $a_{\perp}=$ $4.230 \pm 0.007,4.220 \pm 0.009,4.165 \pm 0.023$, and $4.161 \AA$ for $T_{s}=700,800,900$ and $1000{ }^{\circ} \mathrm{C}$. These values are within the range of previously reported lattice constants, with 4.215-4.303 $\AA$ for $x=$ 
0.49-0.67 [41], 4.161 $\AA$ for $x=0.5$ [60], 4.20-4.27 $\AA$ for $x=0.9-1.6$ [42], 4.07 $\mathrm{A}$ for $x=0.5$ [53],

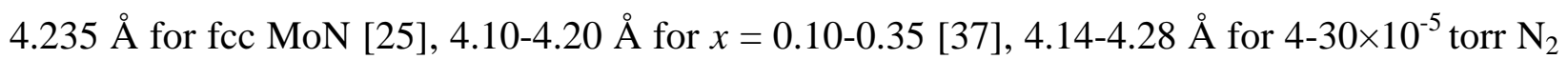
partial pressure during sputter deposition [35], 4.18-4.28 $\AA$ for $\mathrm{N}_{2} /\left(\mathrm{N}_{2}+\mathrm{Ar}_{2}\right)=20-50 \%$ (decreasing to $4.05 \AA$ at $\mathrm{N}_{2} /\left(\mathrm{N}_{2}+\mathrm{Ar}_{2}\right)=80 \%$ ) [38], and 4.19-4.29 $\AA$ for $\mathrm{N}_{2} /\left(\mathrm{N}_{2}+\mathrm{Ar}_{2}\right)=10-50 \%$ [39].

Figure 2 is a plot of the thickness $d$ of $\mathrm{MoN}_{x} / \mathrm{MgO}(001)$ layers vs deposition temperature, as measured by X-ray reflectivity (XRR). The inset is a typical XRR scan from a sample deposited at $T_{s}=1000{ }^{\circ} \mathrm{C}$. It also shows the corresponding curve obtained from data fitting, which matches the measured data including the critical angle for total external reflection at $0.2^{\circ}$, the period of interference fringes as well as the intensity decay, and provides values for the layer thickness of $68.9 \pm 0.1 \mathrm{~nm}$ and the rms surface roughness of $1.4 \mathrm{~nm}$. The main plot in Fig. 2 shows that the thickness decreases with increasing growth temperature, from $d=98.0 \pm 2.0 \mathrm{~nm}$ for $T_{s}=600{ }^{\circ} \mathrm{C}$ to $96.5 \pm 1.0,84.5 \pm 1.0,78.8 \pm 0.2$, and $68.9 \pm 0.1 \mathrm{~nm}$ for $T_{s}=700,800,900$, and $1000{ }^{\circ} \mathrm{C}$, respectively. This monotonic decrease corresponds to a $30 \%$ reduction in the volume of the $\mathrm{MoN}_{x}$ as $T_{s}$ is increased from 600 to $1000{ }^{\circ} \mathrm{C}$, while keeping all other deposition parameters including deposition time, magnetron power, and processing gas pressure constant. As discussed in more detail below, the thickness reduction with increasing temperature is due to a decreasing $\mathrm{N}$-content and a decreasing Mo vacancy concentration, while the Mo content per area remains constant. The error bars in the plot in Fig. 2 are obtained from the XRR fitting procedure and increase with decreasing $T_{s}$, which is due to a decreasing fringe intensity associated with the larger layer thickness and larger surface roughness for lower $T_{s}$. In particular, the rms surface roughness determined from XRR curve fitting decreases with increasing $T_{s}$ from 2.8 to 2.5, 2.4, 2.0, and $1.4 \mathrm{~nm}$ for $T_{s}=600-1000{ }^{\circ} \mathrm{C}$, which is attributed to reduced kinetic roughening at 
elevated $T_{s}$, as previously reported for epitaxial nitrides like $\operatorname{TiN}(001)[61,62]$ and $\mathrm{CrN}(001)$ $[63,64]$.

Figure 3 shows the results obtained from Rutherford backscattering spectroscopy (RBS) analyses for $\mathrm{MoN}_{x} / \mathrm{MgO}(001)$ layers deposited at $T_{s}=600-1000{ }^{\circ} \mathrm{C}$. The plot in Fig. 3(a) is the nitrogen-to-molybdenum ratio $x$, obtained from data fitting of the measured spectra, as illustrated in the inset for a layer deposited at $600{ }^{\circ} \mathrm{C}$. The data points indicate the measured backscattered intensity while the solid line is the result from curve fitting for a simple simulated stack of a $\mathrm{MoN}_{x}$ layer on a semi-infinite $\mathrm{MgO}$ substrate, with the only fitting parameters being the area density $\Theta$ of Mo atoms and the compositional parameter $x$. Due to the relatively low intensity of backscattered $\mathrm{He}$ from the $\mathrm{N}$-atoms, the $\mathrm{N}$-peak intensity has been determined separate from the overall fitting procedure, yielding a reduced uncertainty in the $\mathrm{N}$-content of $\pm 3 \%$, which is also indicated by the error bars in the main plot of Fig. 3(a). The plot shows a relatively large nitrogen-to-molybdenum ratio $x=1.25 \pm 0.03$ for $T_{s}=600{ }^{\circ} \mathrm{C}$. As the deposition temperature increases, $x$ decreases to $1.15 \pm 0.03$ for $T_{s}=700{ }^{\circ} \mathrm{C}, 0.95 \pm 0.03$ for $T_{s}=800{ }^{\circ} \mathrm{C}, 0.75 \pm 0.02$ for $T_{s}$ $=900{ }^{\circ} \mathrm{C}$, and $x=0.69 \pm 0.02$ for $T_{s}=1000{ }^{\circ} \mathrm{C}$. Thus, the $\mathrm{MoN}_{x}$ layers exhibit a range of compositions from overstoichiometric for $T_{s}=600-700{ }^{\circ} \mathrm{C}$, to nearly stoichiometric for $T_{s}=$ $800{ }^{\circ} \mathrm{C}$ to understoichiometric for $T_{s}=900-1000{ }^{\circ} \mathrm{C}$. A similar decrease in the N-content with increasing growth temperature has previously been reported for various epitaxial transition metal nitrides including $\mathrm{NbN}_{x}$ above $900{ }^{\circ} \mathrm{C}$ [10], $\mathrm{CrN}_{x}$ above $730{ }^{\circ} \mathrm{C}$ [7], $\mathrm{HfN}_{x}$ above $650{ }^{\circ} \mathrm{C}$ [14], $\mathrm{WN}_{x}$ above $800{ }^{\circ} \mathrm{C}[20]$, and $\mathrm{TaN}_{x}$ above $400{ }^{\circ} \mathrm{C}[65]$, and has been attributed to nitrogen vacancies that form due to a higher rate of nitrogen recombination and desorption at higher temperature, and the increasing importance of the entropy contribution to the free energy of the 
$\mathrm{N}_{2}$ gas $[10,66]$. However, as discussed below, the deviation from stoichiometry in our $\mathrm{MoN}_{x}$ layers is not only due to $\mathrm{N}$-vacancies but also Mo-vacancies.

Figure 3(b) is a plot of the area density $\Theta$ of Mo atoms in the $\mathrm{MoN}_{x}$ layers, as determined from the RBS spectra. It is nearly independent of $T_{s}$, with values ranging from $3.40 \pm 0.13$ $3.58 \pm 0.12 \times 10^{17}$ atoms $/ \mathrm{cm}^{2}$. That is, within the experimental uncertainty, the amount of Mo deposited during the 6 min layer depositions is temperature-independent. This suggests, however, an increasing layer density since thickness $d$ decreases with increasing $T_{s}$, as presented in Fig. 2. Correspondingly, Fig. 3(b) also shows a plot of the layer density $\rho$, as determined from the atomic mass of Mo and $\mathrm{N}$ and the measured values for $\Theta, d$, and $x$. The density varies only slightly from $\rho=6.9 \pm 0.3 \mathrm{~g} / \mathrm{cm}^{3}$ for $T_{s}=600{ }^{\circ} \mathrm{C}$ to $6.8 \pm 0.3 \mathrm{~g} / \mathrm{cm}^{3}$ at $T_{s}=700{ }^{\circ} \mathrm{C}$, but increases to $7.5 \pm 0.4,7.8 \pm 0.4$, and $8.7 \pm 0.5 \mathrm{~g} / \mathrm{cm}^{3}$ for $T_{s}=800,900$, and $1000{ }^{\circ} \mathrm{C}$, respectively. That is, consistent with the approximately constant Mo content and the decreasing thickness, the density of $\mathrm{MoN}_{x}$ layers increases by $26 \%$ as $T_{s}$ is increased from 600 to $1000{ }^{\circ} \mathrm{C}$.

Figure 4 is a plot of the Mo and $\mathrm{N}$ site occupancies $X_{\mathrm{Mo}}$ and $X_{\mathrm{N}}$ vs deposition temperature $T_{s}=600-1000{ }^{\circ} \mathrm{C}$ for $\mathrm{MoN}_{x}$ layers. The values are obtained by dividing the measured number density of Mo and $\mathrm{N}$ atoms by the anion and cation lattice site density corresponding to a rocksalt structure, where the atomic number density is determined by dividing the area density measured by RBS by the thickness measured by XRR, and the rock-salt structure has a lattice constant measured by XRD. That is, the plot in Fig. 4 is a direct result from data presented in Figs. 1-3. The plotted nitrogen site occupancy is $0.88 \pm 0.04$ for $T_{s}=600{ }^{\circ} \mathrm{C}$. However, as the growth temperature increases, $X_{\mathrm{N}}$ decreases to $0.80 \pm 0.05$ for $T_{s}=700{ }^{\circ} \mathrm{C}$ and to $0.74 \pm 0.05$ for $T_{s}$ $=800{ }^{\circ} \mathrm{C}$, and then to $X_{\mathrm{N}}=0.60 \pm 0.04$ and $0.61 \pm 0.05$ for $T_{s}=900$ and $1000{ }^{\circ} \mathrm{C}$. That is, at low $T_{s}$, the nitrogen site occupancy is relatively high, corresponding to a low $\mathrm{N}$ vacancy concentration of 
$12 \%$ for the layer deposited at $600{ }^{\circ} \mathrm{C}$. Subsequently, $X_{\mathrm{N}}$ drops within the $600-900{ }^{\circ} \mathrm{C}$ temperature range to an approximately constant value for $T_{s} \geq 900{ }^{\circ} \mathrm{C}$. This suggests that temperature activated nitrogen loss during reactive sputter deposition of $\mathrm{MoN}_{x}$ is only partial for $T_{s} \leq 900{ }^{\circ} \mathrm{C}$, while a considerable nitrogen fraction corresponding to a site occupancy of $0.60 \pm 0.04-0.61 \pm 0.05$ is retained up to at least $1000{ }^{\circ} \mathrm{C}$. This is in contrast to the reported complete nitrogen loss and the transition to metallic layers for $\mathrm{MoN}_{x}$ above $800{ }^{\circ} \mathrm{C}$ [42] and $\mathrm{WN}_{x}$ above $820{ }^{\circ} \mathrm{C}$ [67]. The disagreement with Ref. [42] may be related to different temperature calibrations of the deposition systems. Nevertheless, we expect $X_{\mathrm{N}}$ to further decrease at some temperature $>1000{ }^{\circ} \mathrm{C}$.

In contrast, the molybdenum site occupancy plotted in Fig. 4 increases with increasing temperature, from $X_{\mathrm{Mo}}=0.70 \pm 0.04$ for $T_{s}=600-700{ }^{\circ} \mathrm{C}$ to $0.78 \pm 0.05,0.80 \pm 0.05$, and $0.89 \pm 0.06$ for $T_{s}=800,900$ and $1000{ }^{\circ} \mathrm{C}$. This corresponds to a Mo vacancy concentration that decreases by nearly a factor of three, from 30 to $11 \%$, which may be attributed to temperature activated Mo mobility or may be related to the lower nitrogen content which favors a higher Mo occupancy. This is consistent with the density functional calculation results presented below, which suggest an anti-correlation between Mo and $\mathrm{N}$ site occupancies.

Fig. 5 summarizes the results from first-principles calculations which are done to explore thermodynamic (total energy) driving forces which explain the experimentally measured formation of both cation and anion vacancies. The plot in Fig. 5(a) shows the calculated formation energy per atom $E_{f}$ as a function of the N-to-Mo ratio $x$ in $\mathrm{MoN}_{x}$. Each data point corresponds to the energy of one of the over 200 calculated configurations which are obtained by removing some $\mathrm{Mo}$ and/or $\mathrm{N}$ atoms within a super cell of cubic $\mathrm{NaCl}$ structure $\mathrm{MoN}$, as described in more detail in Section 3. That is, all simulated configurations exhibit a cubic 
structure, which was chosen in this study in order to be directly comparable with the experimental results presented above. Each configuration is primarily characterized by the cation and anion site occupancy $X_{\mathrm{Mo}}$ and $X_{\mathrm{N}}$, which determine the composition $x=X_{\mathrm{N}} / X_{\mathrm{Mo}}$. To illustrate this, some of the data points are highlighted with hollow colored symbols that are also connected with lines, where each set of connected points corresponds to configurations with the same supercell size and same $X_{\mathrm{Mo}}$ but varying $X_{\mathrm{N}}$. For example, the curve labeled $X_{\mathrm{Mo}}=0.94$ is obtained using a 32-atom supercell size, where 15 of the 16 cation sites are occupied $\left(X_{\mathrm{Mo}}=\right.$ $15 / 16=0.9375)$ while $X_{\mathrm{N}}$ varies from 0.5 to 1 , corresponding to 8-16 anion sites being occupied, yielding compositions from $x=8 / 15=0.53$ to $x=16 / 15=1.07$. The calculated formation energy of this curve decreases from $E_{f}=-0.226 \mathrm{eV}$ at $x=0.53$ to a minimum of $-0.372 \mathrm{eV}$ at $x=0.67$ and increases again to $-0.128 \mathrm{eV}$ at $x=1.07$. All these energies are negative, indicating that these configurations are stable against complete phase separation into metallic Mo and molecular $\mathrm{N}_{2}$. However, within this constant $X_{\mathrm{Mo}}$ curve, the energy is lowered by nitrogen removal or uptake to achieve $X_{\mathrm{N}}=0.63$ (corresponding to $x=0.67$ ) where $E_{f}$ is at a minimum. We note that the position of this minimum moves to smaller $x$ values if accounting for entropic terms (particularly of the $\mathrm{N}_{2}$ gas) at finite temperatures, and moves to larger $x$ values in the presence of energetic particles or atomic nitrogen, as common during reactive sputter deposition. The other highlighted data point curves in Fig. 5(a) are for other cation site occupancies and super cell sizes, more specifically, 11 Mo atoms in a 24-site cell, 14 and 13 Mo atoms in a 32-site cell, 6 Mo atoms in a 16-site cell, 11 Mo atoms in a 30-site cell, 5 Mo atoms in a 14-site cell, and 8 Mo atoms in a 24site cell. Each of these curves exhibits a minimum which indicates the energetically most favorable nitrogen site occupancy for the given $X_{\text {Mo }}$. The position of the minimum increases from $x=0.67$ for $X_{\text {Mo }}=0.94$ to $x=0.73,0.79,0.92,1.0,1.36$, and 1.40 for $X_{\text {Mo }}=0.92,0.88,0.81$, 
$0.75,0.73$, and 0.71 , indicating that a decreasing Mo site occupancy results in an increasing $\mathrm{N}$ content. Stated differently, an increasing N-to-Mo ratio $x$ results in a decreasing Mo site occupancy. In order to quantify this trend, we consider the configuration with the lowest energy [plotted in Fig. 5(a)] for a given $x$ as most stable, and plot the corresponding $X_{\text {Mo }}$ and $X_{\mathrm{N}}$ vs $x$ in Fig. 5(b).

Figure 5(b) is a plot of the calculated Mo and $\mathrm{N}$ site occupancies of cubic $\mathrm{MoN}_{x}$ as a function $x$. At $x=0.5$, the Mo and $\mathrm{N}$ site occupancies are $X_{\mathrm{Mo}}=1$ and $X_{\mathrm{N}}=0.5$, as expected for a $\mathrm{MoN}_{0.5}$ compound. $X_{\mathrm{N}}$ increases approximately linearly with $x$ to reach a plateau of $X_{\mathrm{N}} \approx 0.75$ at $x=0.87-1.00$, followed by a continued increase to reach $X_{\mathrm{N}}=1.00$ at $x=1.36$. In contrast, the Mo site occupancy decreases from $X_{\mathrm{Mo}}=1.00$ for $x \leq 0.54$ to a plateau of $X_{\mathrm{Mo}}=0.75$ at $x=1.00$ 1.22 , followed by a gradual decrease to $0.73,0.71$, and 0.67 for $x=1.36,1.4$, and 1.5 . The corresponding experimental values are also plotted as open symbols in Fig. 5(b). These measured site occupancies are the same as those plotted in Fig. 4, however, they are plotted here as a function of the measured compositional parameter $x$. There is relatively good agreement between the first-principles predictions and the measurements, with a tendency for slightly lower measured $X_{\mathrm{Mo}}$ and $X_{\mathrm{N}}$ values at all compositions. This deviation can be attributed to the experimental uncertainty but could also indicate a small systematic error in the compositional or thickness measurements.

The good agreement between experiment and simulation confirms that cubic $\mathrm{MoN}_{x}$ simultaneously contains both, cation and anion vacancies. In addition, it clearly shows the anticorrelation between cation and anion site occupancies: As $X_{\mathrm{N}}$ increases, $X_{\mathrm{Mo}}$ decreases, leaving the total cation+anion site occupancy $\left(X_{\mathrm{Mo}}+X_{\mathrm{N}}\right) / 2$ nearly constant between 0.75 and 0.85 . For stoichiometric MoN ( $x=1)$, the most stable cubic phase exhibits the NbO structure, which can 
be described as a $\mathrm{NaCl}$ structure with $X_{\mathrm{Mo}}=X_{\mathrm{N}}=0.75$ [30]. The layer deposited at $T_{s}=800{ }^{\circ} \mathrm{C}$ nearly perfectly matches these expected site occupancies of 0.75 , with the measured $X_{\mathrm{N}}=$ $0.74 \pm 0.05$ and $X_{\text {Mo }}=0.78 \pm 0.05$. In fact, the plot in Fig. 5(b) suggests that an occupancy of 0.75 is preferred for both cation and anion sites, based on the plateaus of $X_{\mathrm{Mo}}$ and $X_{\mathrm{N}}$ at $x=0.87-1.00$ and at $x=1.00-1.22$, respectively. That is, a reduction in the $\mathrm{N}$-to-Mo ratio for moderately understoichiometric compositions $0.87<x<1.00$ is accounted for by an increase in $X_{\text {Mo }}$ while $X_{\mathrm{N}}$ remains constant at 0.75 . Conversely, increasing $x$ above 1.0 results in an increase in $X_{\mathrm{N}}$ but a constant $X_{\mathrm{Mo}}=0.75$ for $1<x<1.22$. This means that deviations from stoichiometric MoN in the $\mathrm{NbO}$ structure (exhibiting $25 \%$ vacancies) is achieved by filling cation or anion vacancies with Mo or $\mathrm{N}$, respectively, yielding under- or over-stoichiometric $\mathrm{MoN}_{x}$, respectively, similar to what has been proposed for deviations from stoichiometry in $\mathrm{WN}_{x}$ [20]. However, as shown in Fig. 5(b), further deviations from stoichiometry including $x<0.87$ and $x>1.22$, cause both $X_{\text {Mo }}$ and $X_{\mathrm{N}}$ to diverge from their "favorite" 0.75 . We note, though, that while $X_{\mathrm{N}}$ decreases considerably below 0.75 and ultimately reaches 0.5 at $x=0.5$, the decrease in $X_{\text {Mo }}$ with increasing $x>1$ is very moderate, suggesting that a NaCl-structure $\mathrm{MoN}$ with more than $25 \%$ cation vacancies becomes increasingly unstable, as also evident from the steeply increasing $E_{f}$ for $x>1.4$ in Fig. 5(a). Nevertheless, the composition that forms during $\mathrm{MoN}_{x}$ layer growth is not purely defined by the $E_{f}$ vs $x$ plotted in Fig. 5(a). This is because, as discussed above, the nitrogen chemical potential is a function of the temperature, $\mathrm{N}_{2}$ partial pressure, as well as the partial pressure and flux of atomic nitrogen and energetic particles including $\mathrm{N}_{2}{ }^{+}$-ions which are common during reactive sputter deposition. In addition, kinetic barriers for adatom diffusion, for $\mathrm{N}_{2}$ dissociation, recombination, and desorption as well as for cation and anion vacancy diffusion 
are expected to play a critical role in the development of the atomic arrangement as well as the composition of a growing $\mathrm{MoN}_{x}$ thin film.

\section{Conclusions}

$\mathrm{MoN}_{x} / \mathrm{MgO}(001)$ layers deposited at $T_{s}=600-1000{ }^{\circ} \mathrm{C}$ exhibit a cubic rock-salt type structure, an 001 orientation, and a N-to-Mo ratio that decreases with increasing $T_{s}$ from $x=$ 1.25-0.69. A combination of composition, thickness, lattice-constant, and atomic area-density measurements indicate that the layers have a rock-salt structure that simultaneously contains both anion and cation vacancies, in good agreement with first-principles calculations that indicate that cubic $\mathrm{MoN}_{x}$ with $0.54<x<1.3$ is most stable if containing both anion and cation vacancies. A quantitative analysis of the Mo and $\mathrm{N}$ site occupancies vs composition $x$ shows good agreement between the measured values and the DFT predictions, and indicates that an occupancy of 0.75 is most preferred for both cation and anion sites, such that stoichiometric cubic MoN is most stable in the $\mathrm{NbO}$ structure and moderate deviations from stoichiometry are realized by filling cation or anion vacancies which increases $X_{\mathrm{Mo}}$ or $X_{\mathrm{N}}$, respectively.

\section{Acknowledgements}

The authors acknowledge support by the National Science Foundation under Grant Nos. 1309490, 1537984, 1234872, and 1629230. 


\section{References}

[1] H. Holleck, Material selection for hard coatings, J. Vac. Sci. Technol. A Vacuum, Surfaces, Film. 4 (1986) 2661. doi:10.1116/1.573700.

[2] J.-E. Sundgren, Microstructural and microchemical characterization of hard coatings, J. Vac. Sci. Technol. A Vacuum, Surfaces, Film. 4 (1986) 2770-2782. doi:10.1116/1.573678.

[3] J. Musil, Hard and superhard nanocomposite coatings, Surf. Coatings Technol. 125 (2000) 322-330. doi:10.1016/S0257-8972(99)00586-1.

[4] G. Abadias, V.I. Ivashchenko, L. Belliard, P. Djemia, Structure, phase stability and elastic properties in the Ti1-xZrxN thin-film system: Experimental and computational studies, Acta Mater. 60 (2012) 5601-5614. doi:10.1016/j.actamat.2012.07.014.

[5] Z.T.Y. Liu, X. Zhou, S. V Khare, D. Gall, Structural, mechanical and electronic properties of $3 \mathrm{~d}$ transition metal nitrides in cubic zincblende, rocksalt and cesium chloride structures: a first-principles investigation., J. Phys. Condens. Matter. 26 (2014) 025404. doi:10.1088/0953-8984/26/2/025404.

[6] J.-E. Sundgren, Structure and properties of TiN coatings, Thin Solid Films. 128 (1985) 21-44. doi:10.1016/0040-6090(85)90333-5.

[7] D. Gall, C.-S. Shin, T. Spila, M. Odén, M.J.H. Senna, J.E. Greene, I. Petrov, Growth of single-crystal $\mathrm{CrN}$ on $\mathrm{MgO}(001)$ : Effects of low-energy ion-irradiation on surface morphological evolution and physical properties, J. Appl. Phys. 91 (2002) 3589. doi:10.1063/1.1446239.

[8] D. Gall, I. Petrov, N. Hellgren, L. Hultman, J.E. Sundgren, J.E. Greene, Growth of polyand single-crystal $\mathrm{ScN}$ on $\mathrm{MgO}(001)$ : Role of low-energy N2+ irradiation in determining texture, microstructure evolution, and mechanical properties, J. Appl. Phys. 84 (1998) 6034-6041.

[9] A.B. Mei, R.B. Wilson, D. Li, D.G. Cahill, A. Rockett, J. Birch, L. Hultman, J.E. Greene, I. Petrov, Elastic constants, Poisson ratios, and the elastic anisotropy of VN(001), (011), and (111) epitaxial layers grown by reactive magnetron sputter deposition, J. Appl. Phys. 115 (2014) 214908. doi:10.1063/1.4881817.

[10] K. Zhang, K. Balasubramanian, B.D. Ozsdolay, C.P. Mulligan, S. V Khare, W.T. Zheng, D. Gall, Growth and mechanical properties of epitaxial $\mathrm{NbN}(001)$ films on $\mathrm{MgO}(001)$, Surf. Coat. Technol. 288 (2016) 105-114.

[11] C.-S. Shin, D. Gall, Y.-W. Kim, P. Desjardins, I. Petrov, J.E. Greene, M. Odén, L. Hultman, Epitaxial $\mathrm{NaCl}$ structure $\delta$-TaN[sub x](001): Electronic transport properties, elastic modulus, and hardness versus N/Ta ratio, J. Appl. Phys. 90 (2001) 2879. doi:10.1063/1.1391214.

[12] A.B. Mei, B.M. Howe, C. Zhang, M. Sardela, J.N. Eckstein, L. Hultman, A. Rockett, I. Petrov, J.E. Greene, Physical properties of epitaxial $\mathrm{ZrN} / \mathrm{MgO}(001)$ layers grown by reactive magnetron sputtering, J. Vac. Sci. Technol. A Vacuum, Surfaces, Film. 31 (2013) 061516. doi:10.1116/1.4825349.

[13] H.S. Seo, T.Y. Lee, J.G. Wen, I. Petrov, J.E. Greene, D. Gall, Growth and physical 
properties of epitaxial HfN layers on $\mathrm{MgO}(001)$, J. Appl. Phys. 96 (2004) 878-884. doi:10.1063/1.1759783.

[14] H.-S. Seo, T.-Y. Lee, I. Petrov, J.E. Greene, D. Gall, Epitaxial and polycrystalline $\mathrm{HfN}[\mathrm{sub} \mathrm{x}](0.8 \leq \mathrm{x} \leq 1.5)$ layers on $\mathrm{MgO}(001)$ : Film growth and physical properties, $\mathrm{J}$. Appl. Phys. 97 (2005) 083521. doi:10.1063/1.1870097.

[15] C.-S. Shin, D. Gall, N. Hellgren, J. Patscheider, I. Petrov, J.E. Greene, Vacancy hardening in single-crystal TiN[sub x](001) layers, J. Appl. Phys. 93 (2003) 6025. doi:10.1063/1.1568521.

[16] S.-H. Jhi, S.G. Louie, M.L. Cohen, J. Ihm, Vacancy hardening and softening in transition metal carbides and nitrides, Phys. Rev. Lett. 86 (2001) 3348-3351. doi:10.1103/PhysRevLett.86.3348.

[17] H. Ihara, Y. Kimura, K. Senzaki, H. Kezuka, M. Hirabayashi, Electronic structures of B1 MoN, fcc Mo2N, and hexagonal MoN, Phys. Rev. B. 31 (1985) 3177-3178.

[18] F.F. Klimashin, H. Euchner, P.H. Mayrhofer, Computational and experimental studies on structure and mechanical properties of Mo-Al-N, Acta Mater. 107 (2016) 273-278. doi:10.1016/j.actamat.2016.01.063.

[19] H. Euchner, P.H. Mayrhofer, Vacancy-dependent stability of cubic and wurtzite Ti1-x Al x N., Surf. Coat. Technol. 275 (2015) 214-218. doi:10.1016/j.surfcoat.2015.05.017.

[20] B.D. Ozsdolay, C.P. Mulligan, K. Balasubramanian, L. Huang, S. V. Khare, D. Gall, Cubic $\beta$-WNx layers: growth and properties vs N-to-W ratio, Surf. Coat. Technol. 304 (2016) 98-107. doi:10.1016/j.surfcoat.2016.06.079.

[21] M.J. Mehl, D. Finkenstadt, C. Dane, G.L.W. Hart, S. Curtarolo, Finding the stable structures of N $1-x$ W x with an ab initio high-throughput approach, Phys. Rev. B. 91 (2015) 184110. doi:10.1103/PhysRevB.91.184110.

[22] K. Balasubramanian, S.V. Khare, D. Gall, Vacancy induced mechanical stabilization of cubic tungsten nitride, Phys. Rev. B. 94 (2016) 174111.

[23] P.J. Rudnik, M.E. Graham, W.D. Sproul, High rate reactive sputtering of MoNx coatings, Surf. Coat. Technol. 49 (1991) 293-297.

[24] R.A. Koshy, M.E. Graham, L.D. Marks, Synthesis and characterization of CrN/Mo2N multilayers and phases of Molybdenum nitride, Surf. Coatings Technol. 202 (2007) 11231128. doi:10.1016/j.surfcoat.2007.07.090.

[25] M. Maoujoud, L. Binst, P. Delcambe, M. Offergeld-Jardinier, F. Bouillon, Deposition parameter effects on the composition and the crystalline state of reactively sputtered molybdenum nitride, Surf. Coatings Technol. 52 (1992) 179-185.

[26] K. Inumaru, K. Baba, S. Yamanaka, Synthesis and Characterization of Superconducting Mo 2 N Crystalline Phase on a Si Substrate : An Application of Pulsed Laser Deposition to Nitride Chemistry, Chem. Mater. 17 (2005) 5935-5940.

[27] A.J. Perry, A.W. Baouchi, J.H. Petersen, S.D. Pozder, Crystal structure of molybdenum nitride films made by reactive cathodic arc evaporation, Surf. Coatings Technol. 54-55 (1992) 261-265. doi:10.1016/S0257-8972(09)90060-3.

[28] K. Khojier, M.R.K. Mehr, H. Savaloni, Annealing temperature effect on the mechanical 
and tribological properties of molybdenum nitride thin films, J. Nanostructure Chem. 3 (2013) 5. doi:10.1186/2193-8865-3-5.

[29] H. Jehn, The molybdenum-nitrogen phase diagram, J. Less-Common Met. 58 (1978) 8598.

[30] Z.T.Y. Liu, X. Zhou, D. Gall, S. V. Khare, First-principles investigation of the structural, mechanical and electronic properties of the NbO-structured $3 \mathrm{~d}, 4 \mathrm{~d}$ and $5 \mathrm{~d}$ transition metal nitrides, Comput. Mater. Sci. 84 (2014) 365-373. doi:10.1016/j.commatsci.2013.12.038.

[31] J. Barbosa, L. Cunha, L. Rebouta, C. Moura, F. Vaz, S. Carvalho, E. Alves, E. Le Bourhis, P. Goudeau, J.P. Rivière, Properties of MoNxOy thin films as a function of the N/O ratio, Thin Solid Films. 494 (2006) 201-206. doi:10.1016/j.tsf.2005.07.192.

[32] H. Ihara, M. Hirabayashi, K. Senzaki, Y. Kimura, H. Kezuka, Superconductivity of B1MoN films annealed under high pressure, Phys. Rev. B. 32 (1985) 1816-1817.

[33] H. Kattelus, M. Ylonen, M. Blomberg, Amorphous Mo-N and Mo-Si-N films in microelectromechanical systems, Fatigue Fract. Eng. Mater. Struct. 28 (2005) 743-749. doi:10.1111/j.1460-2695.2005.00887.x.

[34] G.-C. Lai, M. Takahashi, K. Nobugai, F. Kanamaru, Phase transition in B1-type Mo(1$\mathrm{x}) \mathrm{Nb}(\mathrm{x}) \mathrm{N}$ sputtered films under ammonia annealing, J. Solid State Chem. 82 (1989) 1-7.

[35] F. Shoji, N. Saburo, Structure and Deposition Mechanism of Molybdenum Nitride Films Prepared by Reactive Sputtering, Jpn. J. Appl. Phys. 13 (1974) 1072-1078.

[36] T. Suszko, W. Gulbiński, J. Jagielski, The role of surface oxidation in friction processes on molybdenum nitride thin films, Surf. Coatings Technol. 194 (2005) 319-324. doi:10.1016/j.surfcoat.2004.07.119.

[37] Y.. Shen, Effect of deposition conditions on mechanical stresses and microstructure of sputter-deposited molybdenum and reactively sputter-deposited molybdenum nitride films, Mater. Sci. Eng. A. 359 (2003) 158-167. doi:10.1016/S0921-5093(03)00336-8.

[38] L. Stöber, J.P. Konrath, S. Krivec, F. Patocka, S. Schwarz, A. Bittner, M. Schneider, U. Schmid, Impact of sputter deposition parameters on molybdenum nitride thin film properties, J. Micromechanics Microengineering. 25 (2015) 074001. doi:10.1088/09601317/25/7/074001.

[39] Y. Wang, R.Y. Lin, Amorphous molybdenum nitride thin films prepared by reactive sputter deposition, Mater. Sci. Eng. B. 112 (2004) 42-49. doi:10.1016/j.mseb.2004.05.010.

[40] P. Hones, N. Martin, M. Regula, F. L vy, Structural and mechanical properties of chromium nitride, molybdenum nitride, and tungsten nitride thin films, J. Phys. D. Appl. Phys. 36 (2003) 1023-1029. doi:10.1088/0022-3727/36/8/313.

[41] V.P. Anitha, S. Major, D. Chandrashekharam, M. Bhatnagar, Deposition of molybdenum nitride thin films by r.f. reactive magnetron sputtering, Surf. Coatings Technol. 79 (1996) 50-54. doi:10.1016/0257-8972(95)02425-5.

[42] G. Linker, R. Smithey, O. Meyer, Superconductivity in MoN films with NaCl structure, J. Phys. F Met. Phys. 14 (1984) L115-L119.

[43] E.P. Donovan, G.K. Hubler, M.S. Mudholkar, L.T. Thompson, Ion-beam assisted deposition of molybdenum nitride films, Surf. Coatings Technol. 66 (1994) 499-504. 
[44] M. Mudholkar, L.T. Thompson, Composition and phase control for molybdenum nitride thin films, Mater. Res. Soc. Symp. Proc. 354 (1995) 69-74.

[45] A. Gilewicz, B. Warcholinski, D. Murzynski, The properties of molybdenum nitride coatings obtained by cathodic arc evaporation, Surf. Coatings Technol. 236 (2013) 149158. doi:10.1016/j.surfcoat.2013.09.005.

[46] C. Sarioglu, U. Demirler, M.K. Kazmanli, M. Urgen, Measurement of residual stresses by X-ray diffraction techniques in MoN and Mo2N coatings deposited by arc PVD on highspeed steel substrate, Surf. Coatings Technol. 190 (2005) 238-243. doi:10.1016/j.surfcoat.2004.08.184.

[47] M. Ürgen, O.L. Eryilmaz, A.F. Çakir, E.S. Kayali, B. Nilüfer, Y. Işik, Characterization of molybdenum nitride coatings produced by arc-PVD technique, Surf. Coatings Technol. 94-95 (1997) 501-506. doi:10.1016/S0257-8972(97)00432-5.

[48] K. Inumaru, K. Baba, S. Yamanaka, Structural distortion and suppression of superconductivity in stoichiometric B1-MoN epitaxial thin films, Phys. Rev. B. 73 (2006) 052504. doi:10.1103/PhysRevB.73.052504.

[49] M. Bereznai, Z. Toth, A.P. Caricato, M. Fernandez, A. Luches, G. Majni, P. Mengucci, P.M. Nagy, A. Juhasz, L. Nanai, Reactive pulsed laser deposition of thin molybdenumand tungsten-nitride films, Thin Solid Films. 473 (2005) 16-23. doi:10.1016/j.tsf.2004.06.149.

[50] K. Inumaru, K. Baba, S. Yamanaka, Superconducting molybdenum nitride epitaxial thin films deposited on $\mathrm{MgO}$ and ??-A12O3 substrates by molecular beam epitaxy, Appl. Surf. Sci. 253 (2006) 2863-2869. doi:10.1016/j.apsusc.2006.06.024.

[51] S.L. Roberson, D. Finello, R.F. Davis, Phase control of Mo x N films via chemical vapor deposition, Thin Solid Films. 324 (1998) 30-36.

[52] N.B. Srinivasan, T.B. Thiede, T. de los Arcos, V. Gwildies, M. Krasnopolski, H.-W. Becker, D. Rogalla, A. Devi, R.A. Fischer, Transition metal nitride thin films grown by MOCVD using amidinato based complexes [M(NtBu)2\{(iPrN)2CMe $\} 2](\mathrm{M}=\mathrm{Mo}, \mathrm{W})$ as precursors, Surf. Coatings Technol. 230 (2013) 130-136. doi:10.1016/j.surfcoat.2013.06.024.

[53] H. Luo, G. Zou, H. Wang, J.H. Lee, Y. Lin, H. Peng, Q. Lin, S. Deng, E. Bauer, T.M. McCleskey, A.K. Burrell, Q. Jia, Controlling Crystal Structure and Oxidation State in Molybdenum Nitrides through Epitaxial Stabilization, J. Phys. Chem. C. 115 (2011) 17880-17883. doi:10.1021/jp2048376.

[54] I. Jauberteau, J.L. Jauberteau, P. Goudeau, B. Soulestin, M. Marteau, M. Cahoreau, J. Aubreton, Investigations on a nitriding process of molybdenum thin films exposed to (ArN2-H2) expanding microwave plasma, Surf. Coatings Technol. 203 (2009) 1127-1132. doi:10.1016/j.surfcoat.2008.10.012.

[55] J.S. Chawla, D. Gall, Epitaxial $\mathrm{Ag}(001)$ grown on $\mathrm{MgO}(001)$ and $\mathrm{TiN}(001)$ : Twinning, surface morphology, and electron surface scattering, J. Appl. Phys. 111 (2012) 043708. doi:10.1063/1.3684976.

[56] B.D. Ozsdolay, C.P. Mulligan, M. Guerette, L. Huang, D. Gall, Epitaxial growth and properties of cubic $\mathrm{WN}$ on $\mathrm{MgO}(001), \mathrm{MgO}$ (111) and $\mathrm{Al2O} 3(0001)$, Thin Solid Films. 
590 (2015) 276-283.

[57] L.G. Parratt, Surface studies of solids by total reflection of x-rays, Phys. Rev. 95 (1954) 359-369. doi:10.1103/PhysRev.95.359.

[58] J.P. Perdew, K. Burke, M. Ernzerhof, Generalized Gradient Approximation Made Simple, Phys. Rev. Lett. 77 (1996) 3865-3868. doi:10.1103/PhysRevLett.77.3865.

[59] G. Kresse, D. Joubert, From ultrasoft pseudopotentials to the projector augmented-wave method, Phys. Rev. B. 59 (1999) 1758-1775.

[60] C.L. Bull, T. Kawashima, P.F. McMillan, D. Machon, O. Shebanova, D. Daisenberger, E. Soignard, E. Takayama-Muromachi, L.C. Chapon, Crystal structure and high-pressure properties of $\gamma$-Mo2N determined by neutron powder diffraction and X-ray diffraction, J. Solid State Chem. 179 (2006) 1762-1767. doi:10.1016/j.jssc.2006.03.011.

[61] M.A. Wall, D.G. Cahill, I. Petrov, D. Gall, J.E. Greene, Nucleation kinetics versus nitrogen partial pressure during homoepitaxial growth of stoichiometric TiN(001): A scanning tunneling microscopy study, Surf. Sci. 581 (2005) L122-127. doi:10.1016/j.susc.2005.03.007.

[62] M. Wall, D. Cahill, I. Petrov, D. Gall, J. Greene, Nucleation kinetics during homoepitaxial growth of TiN(001) by reactive magnetron sputtering, Phys. Rev. B. 70 (2004) 1-8. doi:10.1103/PhysRevB.70.035413.

[63] J.R. Frederick, J. D'Arcy-Gall, D. Gall, Growth of epitaxial CrN on $\mathrm{MgO}(001)$ : Role of deposition angle on surface morphological evolution, Thin Solid Films. 494 (2006) 330335. doi:10.1016/j.tsf.2005.08.244.

[64] X.Y. Zhang, D. Gall, Surface mound formation during epitaxial growth of $\mathrm{CrN}(001)$, Thin Solid Films. 518 (2010) 3813-3818. doi:10.1016/j.tsf.2009.12.085.

[65] C.-S. Shin, Y.-W. Kim, N. Hellgren, D. Gall, I. Petrov, J.E. Greene, Epitaxial growth of metastable $\delta$-TaN layers on $\mathrm{MgO}(001)$ using low-energy, high-flux ion irradiation during ultrahigh vacuum reactive magnetron sputtering, J. Vac. Sci. Technol. A Vacuum, Surfaces, Film. 20 (2002) 2007. doi:10.1116/1.1513639.

[66] K. Zhang, K. Balasubramanian, B.D. Ozsdolay, C.P. Mulligan, S. V. Khare, W.T. Zheng, D. Gall, Epitaxial NbCxN1-x (001) layers: growth, mechanical properties, and electrical resistivity, Surf. Coat. Technol. 277 (2015).

[67] Y.G. Shen, Y.W. Mai, W.E. Mcbride, Q.C. Zhang, D.R. Mckenzie, Structural properties and nitrogen-loss characteristics in sputtered tungsten nitride films, (2000) 257-264. 


\section{Figure Captions}

Figure 1: The out-of-plane lattice constant $a_{\perp}$ vs growth temperature $T_{s}=600-1000{ }^{\circ} \mathrm{C}$, as determined from XRD $\theta-2 \theta$ scans from $\mathrm{MoN}_{x} / \mathrm{MgO}(001)$ layers. The inset is a section of a typical XRD pattern, showing the $\mathrm{MoN}_{x}$ layer peak using a 30-fold magnified (red) curve, from a layer grown at $T_{s}=1000{ }^{\circ} \mathrm{C}$.

Figure 2: The layer thickness $d$ vs growth temperature $T_{s}$ of epitaxial $\mathrm{MoN}_{x} / \mathrm{MgO}(001)$ layers, obtained from XRR analyses. The inset shows a typical XRR spectrum and corresponding curve from data fitting, from a 69-nm-thick $\mathrm{MoN}_{x}(001)$ layer deposited at $T_{s}=1000{ }^{\circ} \mathrm{C}$.

Figure 3: (a) The N-to-Mo ratio $x$ and (b) the area density $\Theta$ and volume density $\rho$, of $\mathrm{MoN}_{x} / \mathrm{MgO}(001)$ layers vs deposition temperature $T_{s}$, measured by $\mathrm{RBS}$. The inset shows a typical RBS spectrum including the simulated fitting curve for the layer deposited at $T_{s}=600{ }^{\circ} \mathrm{C}$.

Figure 4: Mo and $\mathrm{N}$ site occupancies $X_{\mathrm{Mo}}$ and $X_{\mathrm{N}}$ vs deposition temperature $T_{s}$, for $\mathrm{MoN}_{x}(001)$ layers where a complete occupancy $X_{\mathrm{Mo}}=X_{\mathrm{N}}=1$ corresponds to $\mathrm{MoN}$ in the rock-salt structure.

Figure 5: First principles predictions of (a) the formation energy per atom $E_{f}$ and (b) the Mo and $\mathrm{N}$ site occupancies $X_{\mathrm{Mo}}$ and $X_{\mathrm{N}}$ vs concentration $x$ in $\mathrm{MoN}_{x}$. The lines and open symbols in (a) indicate energies calculated for specific Mo site occupancies, as labeled. The open symbols in (b) are the experimental data points. 


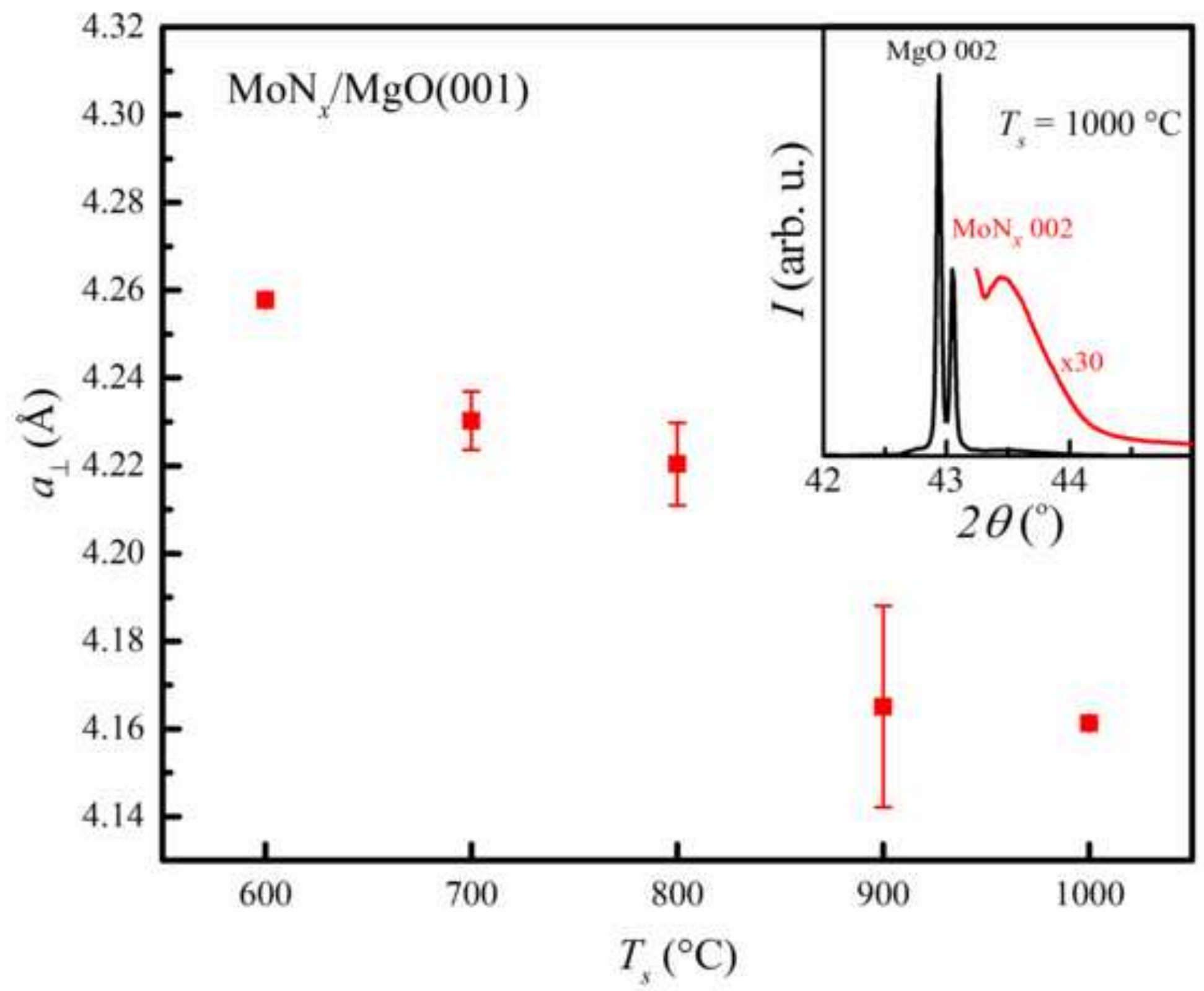




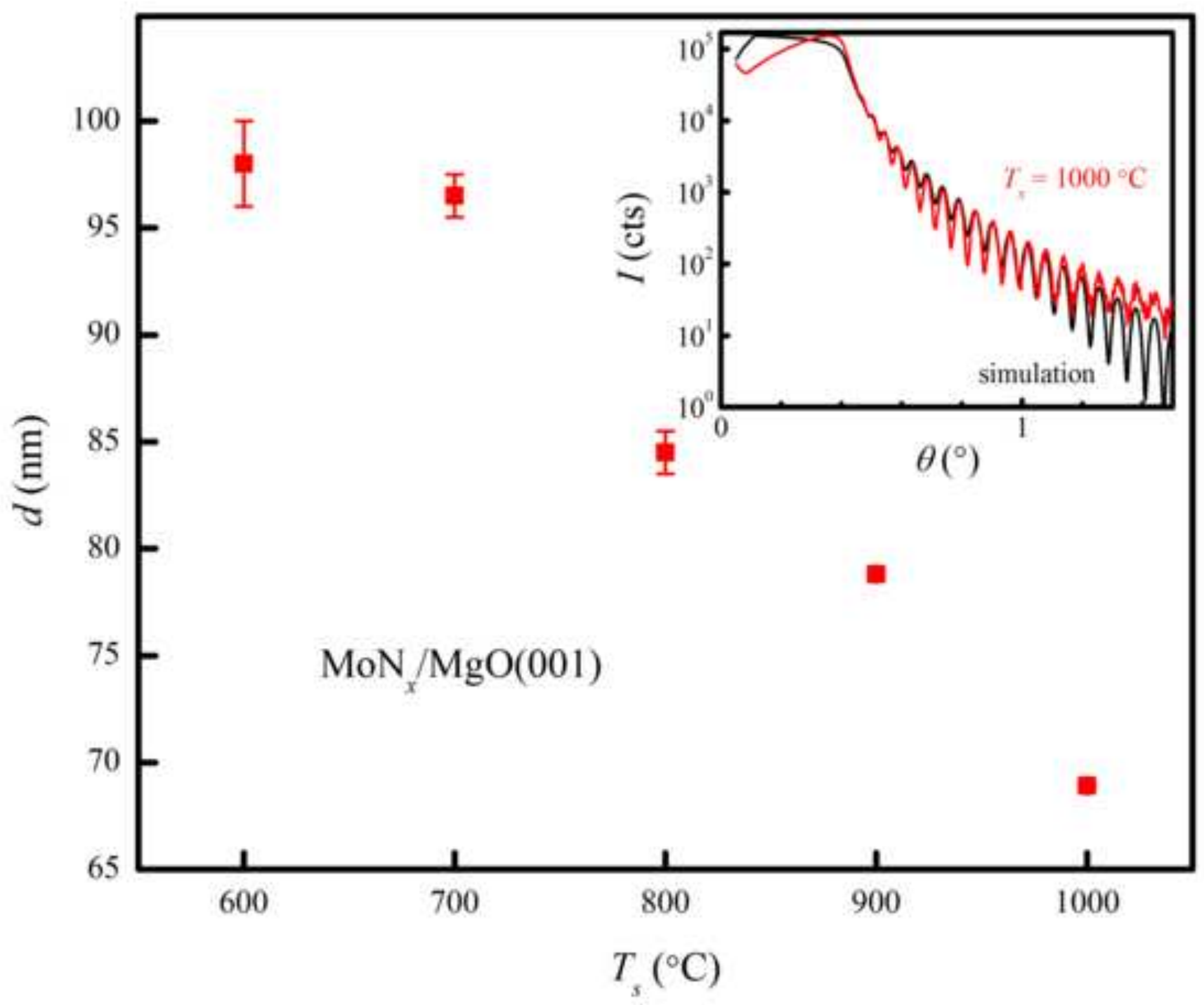




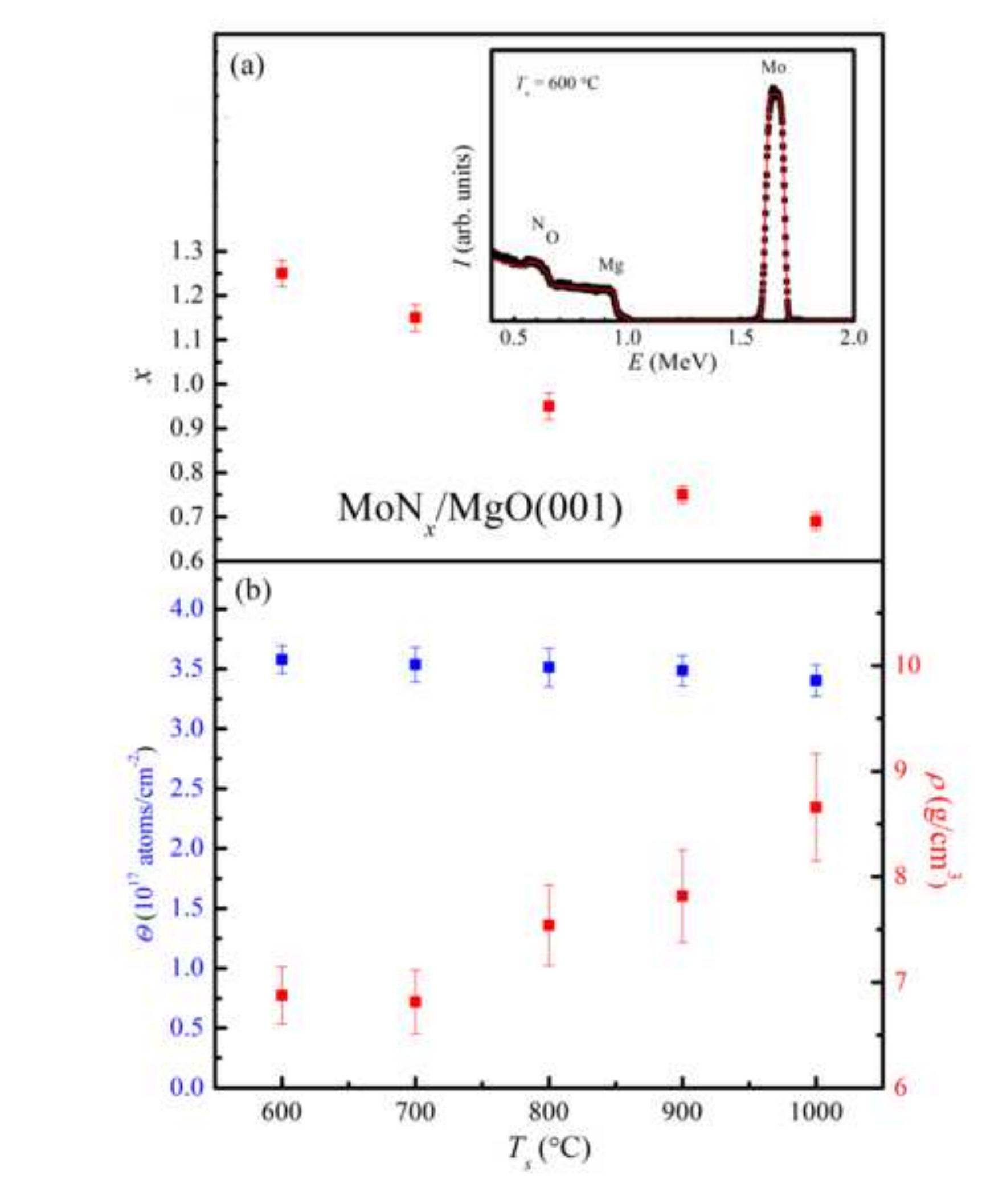

Figure 3

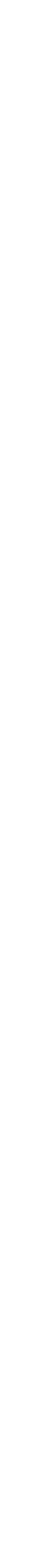

3

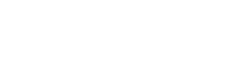

(1)
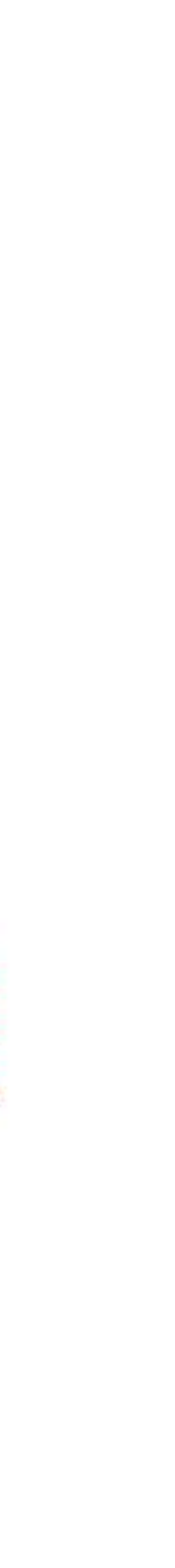

Figure
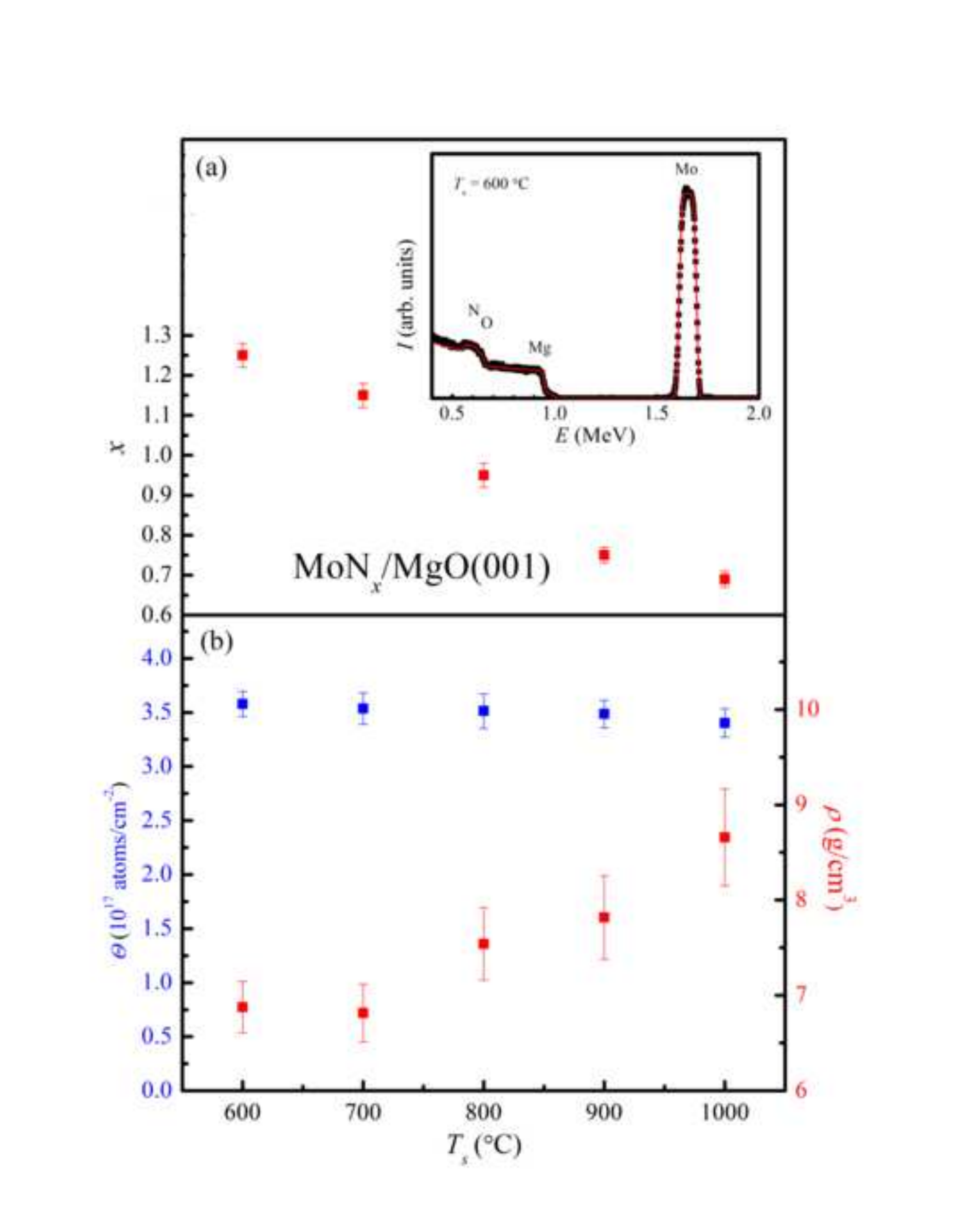


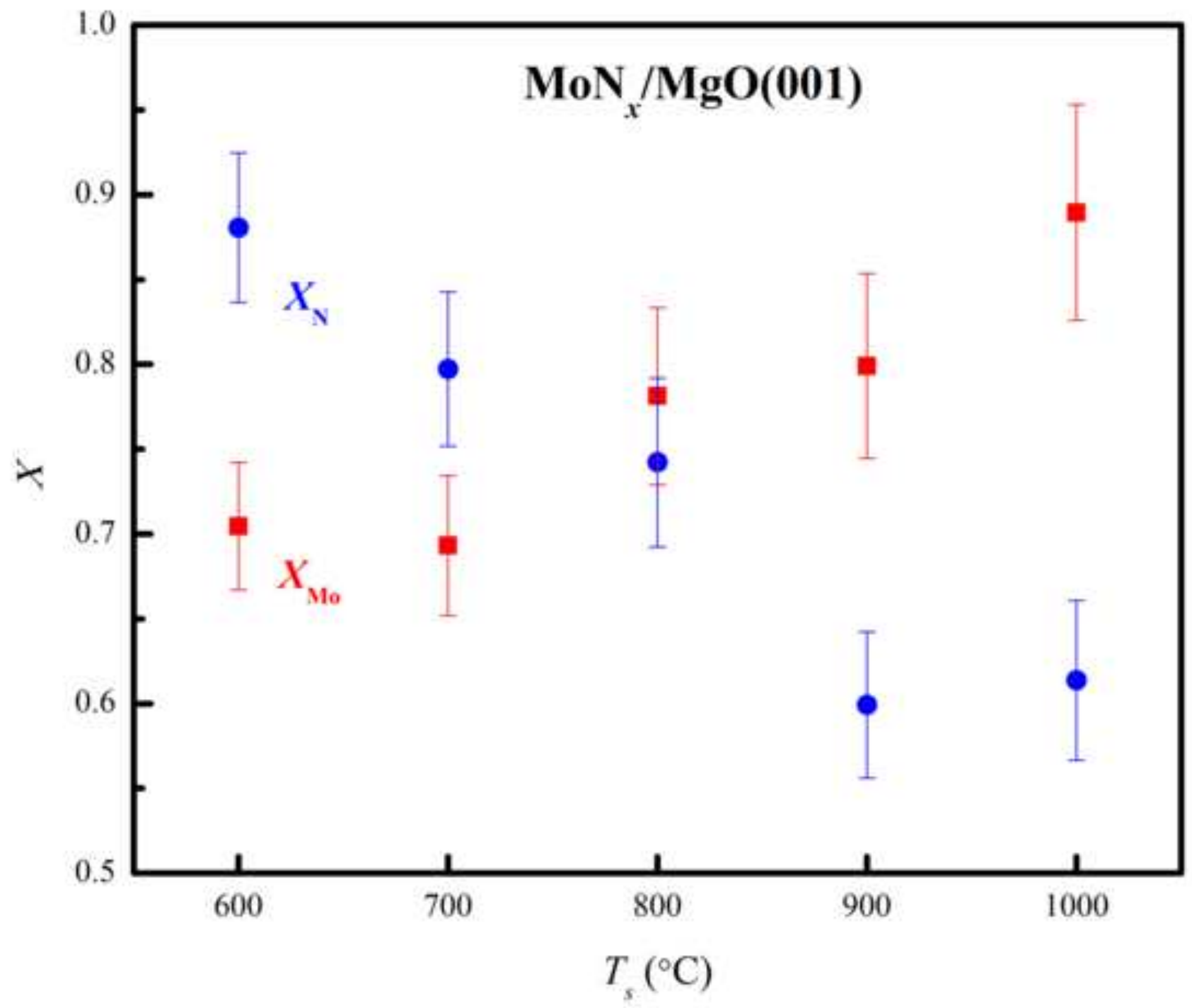




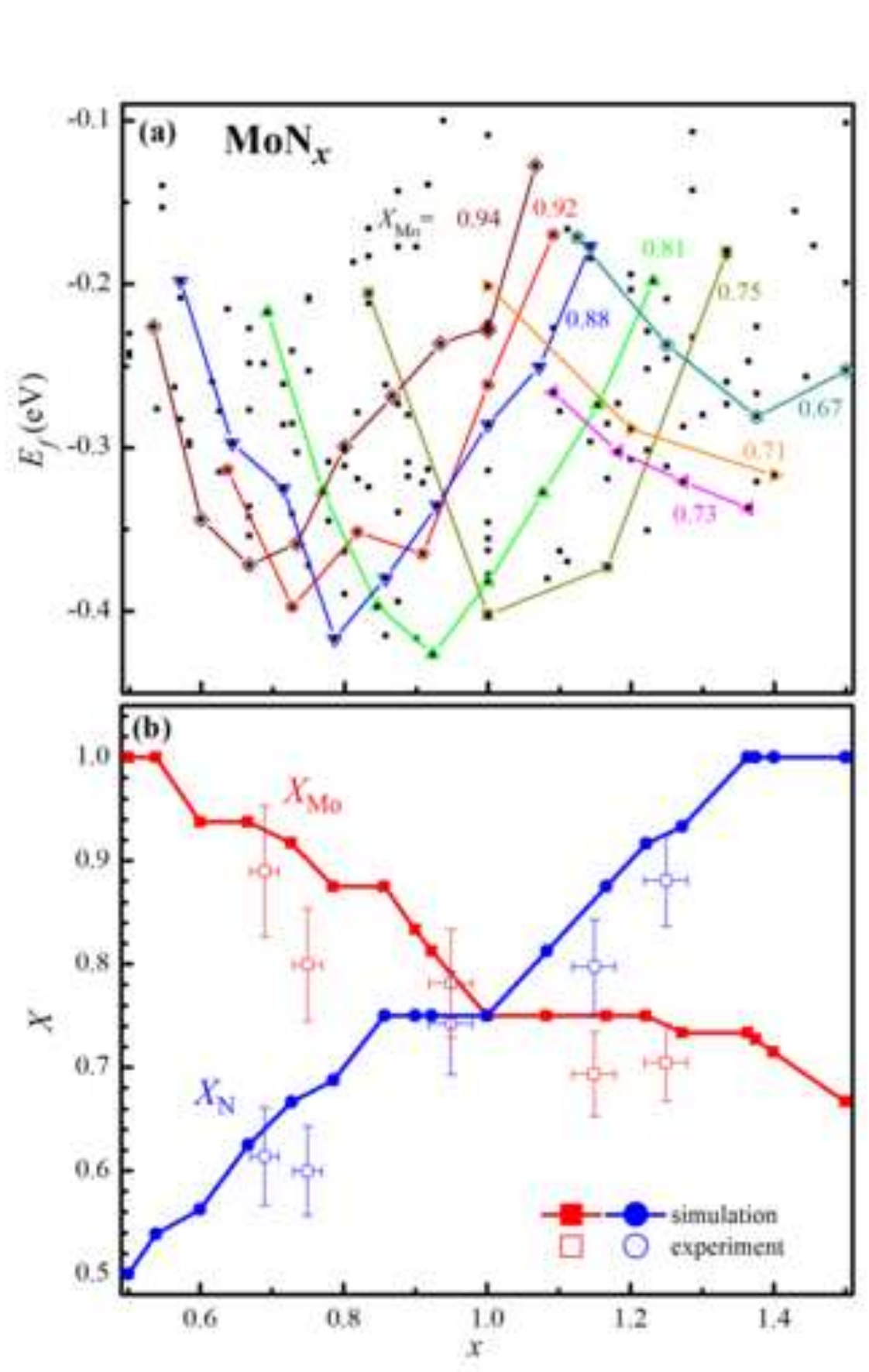

